\title{
Análise da Imagem dos Turistas quanto ao Desenvolvimento do Turismo em Perobas, Touros-RN
}

\author{
Analysis of Tourist Image for Tourism Development in Perobas, Touros-RN \\ Análisis de la Imagen de Turistas para el Desarrollo del Turismo en Perobas, Touros-RN
}

Wagner Araújo Oliveira ${ }^{1}$

Clébia Bezerra da Silva

\section{Resumo}

O presente artigo tem como objetivo avaliar a imagem dos turistas quanto ao desenvolvimento do turismo nos recifes de corais de Perobas. A comunidade de Perobas situa-se no município de Touros-RN, distante aproximadamente $90 \mathrm{~km}$ da Capital do Estado - Natal, o qual faz parte da área de influência direta da Área de Proteção Ambiental dos Recifes de Corais juntamente com os municípios de Maxaranguape e Rio do Fogo. Os processos metodológicos consistiram inicialmente em revisão da literatura, depois uso de questionários como instrumento de coleta de dados questionários, visita in loco e capturas de imagens. Os resultados obtidos mostraram que os principais destinos de origens dos turistas são São Paulo e Rio de Janeiro, que o principal motivo para visitar Perobas é o mergulho, e as primeiras informações do local são dadas pelas agências de Natal. Além disso, mostraram o interesse dos turistas em visitar um centro de informações do local, já quanto à verificação da satisfação dos passeios observouseque eles manifestaram-se relativamente satisfeitos. No entanto, também verificou práticas inadequadas por parte dos turistas, como pisoteio de corais, alimentação artificial aos peixes, coletas de corais, devido à falta de fiscalização e a não obtenção de informações sobre as normas do local.

Palavras-chaves: Turismo; Comunidade de Perobas; Turistas.

\begin{abstract}
This article aims to evaluate the image of tourists for the development of tourism in reef corals Perobas. The Perobas community is located in the town of Touros-RN, distant about $90 \mathrm{~km}$ from the state capital, Natal which, along with the municipalities of Maxaranguape and Rio do Fogo are part of the area of direct influence of the Environmental Protection Area

\footnotetext{
${ }^{1}$ Mestrando em Turismo pelo Programa de Pós-graduação em Turismo pela Universidade Federal do Rio Grande do Norte (PPGTUR/UFRN). Graduado em Turismo pela Universidade Federal do Rio Grande do Norte (UFRN). Especialização em Gestão Ambiental pelo Instituto Federal de Educação, Ciência e Tecnologia do Rio Grande do Norte (IFRN). Natal, Rio Grande do Norte, Brasil. E-mail: wagnercnrn@ hotmail.com

${ }^{2}$ Mestra em Desenvolvimento e Meio Ambiente e Especialização em Educação e Sustentabilidade Ambiental pela Universidade Federal do Rio Grande do Norte (UFRN). Graduação em Turismo pela Universidade Federal do Rio Grande do Norte (UFRN). Professora Assistente da Universidade Federal do Rio Grande do Norte (UFRN). Natal, Rio Grande do Norte, Brasil. E-mail: clabiabsilva@yahoo.com.br
} 
Recifes de Corais. The methodological procedures initially consisted of literature review, questionnaires used as data collection instrument, on-site visit and snapshots. The results show that the main destinations of origin of the tourists are from São Paulo and Rio de Janeiro, the main reason to visit Perobas is diving, and obtaining location information are for the Natal agencies showed interest to visit a center for location information, as check rides satisfaction showed relatively satisfied in which the site has met expectations, however, also found inappropriate practices by tourists, as trampling of corals, artificial feeding to fish, collections corals, due to lack of supervision and failure to provide information on the rules of the site.

Keywords: Tourism; Community Perobas; Tourists.

\section{Resumen}

Este artículo tiene como objetivo evaluar la imagen de los turistas para el desarrollo del turismo en los arrecifes de coral Perobas. La comunidad Perobas se encuentra en la localidad de Touros-RN, distante a unos $90 \mathrm{~km}$ de la capital del estado - Natal, junto con los municipios de Maxaranguape y Rio do Fogo son parte de la zona de influencia directa del Área de Protección Ambiental Recifes de Corais. Los procedimientos metodológicos inicialmente consistieron en revisión de la literatura, los cuestionarios utilizados como instrumento de recolección de datos, visita in situ y las instantáneas. Los resultados muestran que los principales destinos de origen de los turistas son de São Paulo y Rio de Janeiro, la razón principal para visitar Perobas es el buceo, y la obtención de información de ubicación son para las agencias de Natal. Además, mostraron interés para visitar un centro de información de la ubicación, Ya en la satisfacción de los paseos de verificación se observó que se manifestaron relativamente satisfechos. Sin embargo, también se encontró prácticas inadecuadas por parte de turistas, como el pisoteo de los corales, la alimentación artificial de los peces, las colecciones de coral debido a la falta de supervisión y la imposibilidad de obtener información sobre las reglas del sitio.

Palabras clave: Turismo; Perobas Comunidad; Turistas.

\section{Introdução}

O turismo é uma das principais atividades econômicas em escala global, movimentando milhões de pessoas em todo o mundo, gerando divisas para os países e influenciando os centros receptores para se adequarem a demanda e os segmentos que vão surgindo. (ORGANIZAÇÃO MUNDIAL DO TURISMO, 2002).

Os segmentos que mais crescem são aqueles que estão atrelados ao contato com a natureza, pois as pessoas estão cada vez mais à procura de lugares de caráter natural e tranquilo, tentando fugir do estresse advindo da vida agitada dos grandes centros urbanos (DIAS, 2008). 
Nesse sentido, a oferta desses lugares também vem crescendo de forma proporcional, onde inclui as unidades de conservação (UCs) ou áreas naturais protegidas que têm por objetivo proteger ecossistemas de relevância ecológica como também o desenvolvimento do turismo. Em função disso há acelerado crescimento de criação de áreas protegidas no mundo e no Brasil, como pode ser visto em Dias (2008, p.135), "as áreas naturais protegidas em todo mundo vem recebendo um fluxo cada vez maior de turistas, e a tendência é o aumento dessa procura".

As unidades de conservação, como denominadas no Brasil, fazem parte de uma política instituída pelo governo, criadas com a intenção de proteger e conservar as áreas de interesse ecológico e ecossistemas frágeis. O Sistema Nacional de Unidades de Conservação (SNUC) categorizou as unidades de conservação em dois grupos, as de proteção integral e as de uso sustentável, estas tendo a permissão de visitação turística (COSTA, 2002). Dentro das UCs há as Unidades de Conservação Marinha (UCMs), que têm por objetivo proteger a biodiversidade marinha.

No Brasil, o ambiente marinho corresponde $3.555 .796 \mathrm{~km}$, dos quais $54.390 \mathrm{~km}$ fazem parte de alguma UC, tanto de proteção integral quanto de uso sustentável, totalizando 120 unidades de conservação, ou seja, 1,57\% do todo (PRATES, 2012, p. 127). Entretanto, os ambientes marinhos e costeiros do Brasil têm sofrido um processo de degradação nos últimos anos, gerado pela crescente pressão da atividade humana sobre os recursos naturais marinhos (SANTOS; CÂMARA, 2002).

O turismo depende dos ambientais recifais para geração de divisas em países da região costeira e marinha. Em todo o mundo, esse turismo vem crescendo e gerando muitas riquezas econômicas para essas regiões, nos locais como o Caribe, Florida Keys National Marine Sanctuary Park (EUA), Parque Marinho da Grande Barreira de Recifes - GBR (AUS), Parque Nacional Marinho de Fernando de Noronha (PARNAMAR-FN), a geração de divisas através do turismo marinho apresenta-se em grande escala, gerando bilhões de dólares (KUNZMANN, 2004).

O Rio Grande do Norte possui três unidades de conservação marinha que são: Reserva Biológica Marinha Atol das Rocas, Reserva de Desenvolvimento Sustentável Ponta do Tubarão e Área de Proteção ambiental Recifes de Corais (APARC). Na APARC as principais atividades desenvolvidas são o turismo e a pesca artesanal. O turismo é concentrado nos passeios aos recifes de corais. De acordo com o plano de manejo da APARC, existem três parrachos (nome aos recifes de corais pela comunidade) passivos a visitação turística, a saber: 
parracho de Maracajaú, que já possui uma infraestrutura turística e uma visitação consolidada; parracho de Perobas, que a visitação ainda é realizada de forma esporádica, por meio de duas empresas; e parracho de Cioba, que ainda não é realizada nenhuma visitação turística.

Diante disso, o presente artigo busca avaliar a imagem dos turistas quanto ao desenvolvimento do turismo nos recifes de corais em Perobas, Touros-RN.

\section{2. Área de Proteção Ambiental Recifes de Corais}

A APARC foi criada através do Decreto estadual $n^{\circ} 15.476$, de 6 de junho de 2001, sua área é de 32500ha. Ela engloba três parrachos: Cioba, Maracajaú e Rio do Fogo. A qual está localizada na plataforma rasa adjacente aos municípios de Rio do Fogo, Touros e Maxaranguape (Figura 1) (AMARAL, et al., 2005).

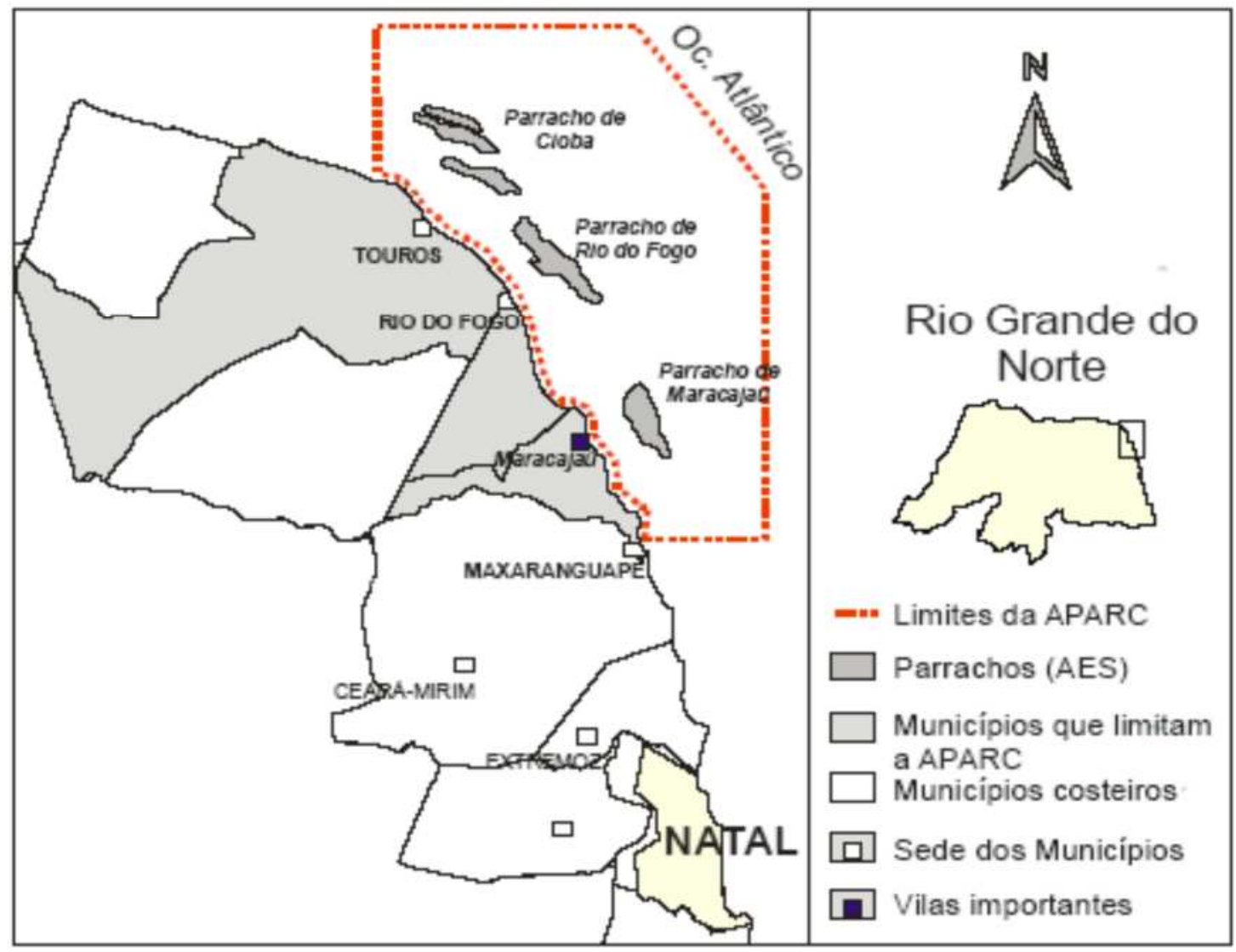

Fonte: AMARAL et al, 2013.

Figura 1: Localização da APARC 
Os objetivos de criação da APARC foram: proteger a biodiversidade e a vida marinha presentes na área com ocorrência de recifes de corais e suas adjacências; controlar e normatizar as práticas de ecoturismo comercial, do mergulho e da pesca local; desenvolver na comunidade, nos empreendedores e visitantes uma consciência ecológica e conservacionista sobre o patrimônio natural e os recursos ambientais marinhos; incentivar a utilização de equipamentos de pesca artesanal ecologicamente corretos e incentivar a realização de pesquisas para a identificação e o comportamento dos organismos marinhos visando propiciar um maior conhecimento do ecossistema (RIO GRANDE DO NORTE, 2001)

O Conselho Gestor é presidido pelo IDEMA e por membros representantes de cada um dos seguintes órgãos, entidades e segmentos (RIO GRANDE DO NORTE, 2001, p.3).

- Secretaria de Estado de Turismo;

- Prefeituras Municipal de Touros, Rio do Fogo e Maxaranguape;

- Câmara dos vereadores de Touros, Rio do Fogo e Maxaranguape;

- Empresários do turismo que praticam passeios marítimos na área da APA;

- Mergulhadores;

- Organização não governamental ambientalista sediada e atuante nos Municípios abrangidos pela APA;

- Gerência Regional do Patrimônio da União (GRPU);

- Instituto Brasileiro do Meio Ambiente e dos Recursos Naturais Renováveis (IBAMA);

- Universidade Federal do Rio Grande do Norte

- Secretaria Especial de Agricultura e Pesca (SEAP)

- Colônia de pescadores de Maracajaú, Touros e Rio do Fogo;

- Associação de moradores das praias dos Municípios de Touros.

No entanto, existem assentos que não possuem representantes que são Colônia de Pescadores de Touros, associação de moradores das praias do município de Maxaranguape e dos empresários.

As principais atividades desenvolvidas na APARC são o turismo e a pesca. Em Maracajaú o turismo encontra-se consolidado, enquanto a pesca está descaracterizando-se, e em Perobas o turismo ainda está em fase inicial, enquanto a pesca é sua principal atividade econômica. $\mathrm{O}$ turismo se concentra nos passeios aos parrachos e o maior fluxo encontra-se na comunidade de Maracajaú, já em Perobas duas empresas fazem os passeios.

Perobas encontra-se localizada no município de Touros-RN, distante de aproximadamente 90 km da Capital do Estado - Natal, o qual, juntamente com os municípios de Maxaranguape e Rio do Fogo, faz parte da área de influência direta da Área de Proteção Ambiental dos Recifes de Corais (ver na figura 2) 


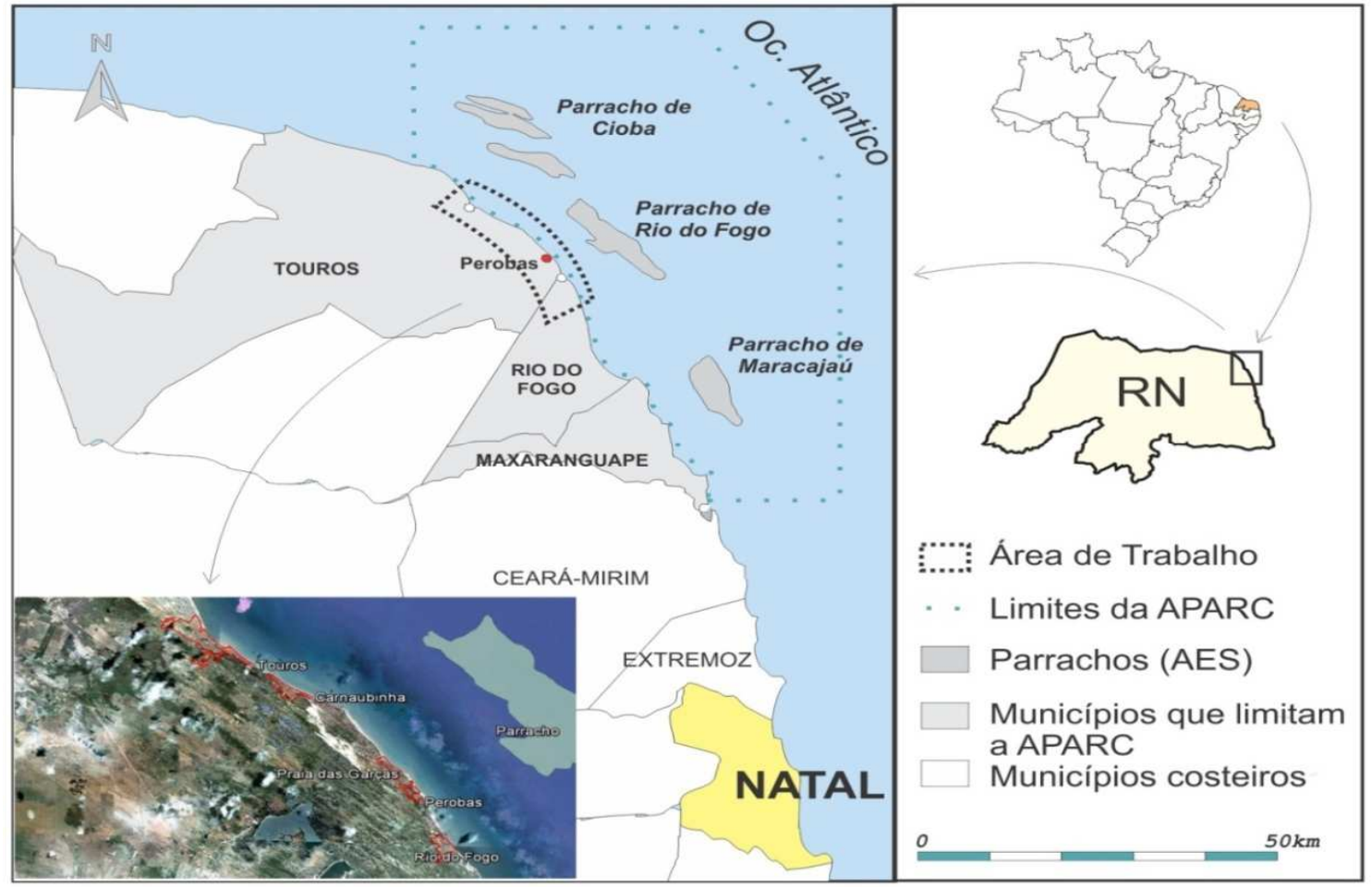

Figura 2: Localização da comunidade de Perobas

Fonte: AMARAL et al, 2013.

\section{Metodologia}

O presente estudo caracteriza-se como exploratório e adotou uma abordagem qualiquantitativa. Para realização da pesquisa, o universo considerado foram os turistas que fizeram os passeios ao parracho por meio das duas empresas existentes. Com relação à amostra dos turistas, a escolha foi não probabilística por conveniência. Esse método justificase pois não houve a disponibilização dos dados existentes em tempo hábil para esta pesquisa. Desse modo, foram entrevistados 67 turistas, quanto à variação do total da frequência dos entrevistados se dá pela não resposta por parte dos entrevistados.

Para coleta de dados foi utilizado questionários, a aplicação foi realizada no período que compreende de 9 a 13 de janeiro de 2014, considerando que o mês de Janeiro é o período da alta estação, ou seja, o período no qual existe o maior fluxo turístico nos destinos, para tanto é o período mais adequado para a realização de pesquisa na área do turismo (ORGANIZAÇÃO MUNDIAL DO TURISMO, 2002). 
A aplicação dos questionários foi feita após os grupos de turistas realizarem o passeio e que, posteriormente eram direcionados aos restaurantes para fazer refeição, e antes de serem servidos eram abordados pelos aplicadores.

Após os dados obtidos foi feito a tabulação de forma quantitativa "a operação essencial da tabulação é a contagem para determinar o número de casos que estão nas várias categorias" (DENCKER, 2002, p. 163).

As questões semiabertas, fechadas e de múltipla escolha foram analisadas de forma quantitativa, através de análise descritiva (porcentagem, média, frequência). Para as questões abertas foi feito a análise de conteúdo "que consiste em um conjunto de técnicas de análise das comunicações" (BARDIN, 2007, p. 27).

Para tabulação da análise de conteúdo, inicialmente foi feito a codificação das respostas e posteriormente realizado a categorização das respostas em símbolos. E, de acordo com Dencker (2002, p.163), isso "é o processo técnico pelo qual são categorizados os dados. Através da codificação os dados brutos são transformados em símbolos [...]". Por exemplo, para a categoria Ajuda a Preservar o Local, foram agrupadas respostas como "protege o meio ambiente", "manter sempre a proteção" e "ajuda a preservação". Feito isso, foi calculada a frequência das repostas. Logo, foi possível ter com exatidão a quantidade de vezes que cada símbolo (e seus sinônimos) aparecia. Os dados foram tabulados e analisados com o apoio software estatístico Statistical Package for the Social Sciences (SPSS® 12.0).

\section{Resultados}

O perfil dos turistas está representado na tabela 1, quanto ao gênero dos entrevistados $51,5 \%$ correspondem ao gênero masculino, enquanto $48,5 \%$ ao gênero feminino. No tocante ao estado civil, a maioria é de pessoas casadas (56,7 \%). Quanto à renda familiar, a maioria tem renda acima de 8.000 reais, sendo que $20 \%$ correspondem entre $\mathrm{R} \$ 8001$ e $\mathrm{R} \$ 10.000$, e com o maior percentual, de 22,2 \% acima de $\mathrm{R} \$ 10.000$. Diante disso, pode-se afirmar que os turistas possuem um considerável poder aquisitivo, evidenciando a possibilidade de maior gasto durante a viagem. A média de idade é de 34 anos.

Quanto ao nível de escolaridade, observa-se que a maioria tem o ensino superior $(62,1 \%)$ enquanto só $1,5 \%$ possuem o ensino fundamental incompleto. Logo, analisa-se que o grau de 
instrução dos turistas é elevado. Com relação à profissão 32,3\% são funcionários públicos, $32,3 \%$ profissionais liberais, 7,7\% autônomos, 9,2\% são aposentados e $20 \%$ exercem outras atividades profissionais. No tocante a religião, 63,6 \% dizem ser católicos, 6,2\% protestantes, 13,8\% são da religião espírita, $12,3 \%$ sem religião e $3,1 \%$ são de outras religiões. Foi constatado que a origem dos turistas é dos dois principais centros urbanos do Brasil, que também são os maiores centros emissores de turistas onde $48 \%$ são de São Paulo e 12 \% do Rio de Janeiro. Turista internacional corresponde apenas $2 \%$.

Tabela 1: Perfil dos turistas

\begin{tabular}{|c|c|c|c|}
\hline \multirow{3}{*}{ Gênero } & & $f$ & $\%$ \\
\hline & Masculino & 34 & 51,5 \\
\hline & Feminino & 32 & 48,5 \\
\hline \multicolumn{2}{|l|}{ TOTAL } & 66 & 100 \\
\hline \multirow{4}{*}{ Estado Civil } & Casado & 38 & 56,7 \\
\hline & Solteiro & 25 & 37,3 \\
\hline & Separado/desquitado & 3 & 4,5 \\
\hline & Viúvo & 1 & 1,5 \\
\hline \multicolumn{2}{|l|}{ TOTAL } & 67 & 100 \\
\hline \multirow[t]{6}{*}{ Renda Familiar } & Até R\$ 2.000 & 6 & 9,5 \\
\hline & Entre $\mathrm{R} \$ 2.001$ e $\mathrm{R} \$ 4.000$ & 12 & 19 \\
\hline & Entre $\mathrm{R} \$ 4001$ e $\mathrm{R} \$ 6.000$ & 11 & 17,5 \\
\hline & Entre $\mathrm{R} \$ 6.001$ e $\mathrm{R} \$ 8.000$ & 7 & 11,1 \\
\hline & Entre $\mathrm{R} \$ 8001$ e $\mathrm{R} \$ 10.000$ & 13 & 20,6 \\
\hline & Acima de $\mathrm{R} \$ 10.000$ & 14 & 22,2 \\
\hline \multicolumn{2}{|l|}{ TOTAL } & 62 & 100 \\
\hline \multirow[t]{6}{*}{ Profissão/Ocupação } & Profissional Liberal & 21 & 32,3 \\
\hline & Funcionário Público & 17 & 26,2 \\
\hline & Autônomo & 5 & 7,7 \\
\hline & Aposentado - Pensionista & 3 & 4,6 \\
\hline & Estudante & 6 & 9,2 \\
\hline & Outra & 13 & 20,0 \\
\hline \multicolumn{2}{|l|}{ TOTAL } & 65 & 100 \\
\hline \multirow[t]{6}{*}{ Nível Educacional } & Ensino fundamental incompleto & 1 & 1,5 \\
\hline & Ensino fundamental completo & 3 & 4,5 \\
\hline & Ensino médio incompleto & 5 & 7,6 \\
\hline & Ensino médio completo & 6 & 9,1 \\
\hline & Ensino superior incompleto & 10 & 15,1 \\
\hline & Ensino superior completo & 41 & 62,1 \\
\hline \multicolumn{2}{|l|}{ TOTAL } & 66 & 100 \\
\hline \multirow{5}{*}{ Religião } & Católico & 42 & 64,6 \\
\hline & Protestante & 4 & 6,2 \\
\hline & Espírita & 9 & 13,8 \\
\hline & Sem religião & 8 & 12,3 \\
\hline & Outra & 2 & 3,1 \\
\hline \multicolumn{2}{|l|}{ TOTAL } & 65 & 100 \\
\hline
\end{tabular}

Fonte: Dados da pesquisa, 2014. 
Quanto obtenção das informações sobre Perobas, mais da metade dos turistas $(64,6 \%)$ obtém as primeiras informações sobre o parracho de Perobas ao chegar à Natal, enquanto que 25,4\% obtêm antes de chegar à Natal (Tabela 2).

Tabela 2: Obtenção das primeiras informações sobre o parracho de Perobas

\begin{tabular}{l|l|c|c}
\hline \multirow{4}{*}{ Primeiras informações } & & $\boldsymbol{f}$ & $\boldsymbol{\%}$ \\
\cline { 2 - 4 } & Antes de chegar à Natal & 42 & 64,6 \\
\cline { 2 - 4 } & Ao chegar à Natal & 24 & 36,3 \\
\hline \multirow{2}{*}{ TOTAL } & $\mathbf{6 6}$ & $\mathbf{1 0 0}$ \\
\hline
\end{tabular}

Fonte: Dados da pesquisa, 2014.

A pesquisa realizada em Maracajaú por Silva (2008) mostra um resultado parecido, no qual $65,3 \%$ disseram ter as primeiras informações ao chegar à Natal.

Os principais meios de obtenção de informações sobre o Parracho são as de agências de viagens $(48,5 \%)$, por terceiros $(19,7 \%)$, por meio da internet $(10,6 \%)$, não sabia, estava incluso no pacote $(9,1 \%)$, ficou sabendo no hotel $(7,6 \%)$, outros $(3,0 \%)$ e em agência de viagens do meu Estado (1,5\%) (ver tabela 3$)$.

Tabela 3: Meios da Obtenção de informações sobre o parracho de Perobas

\begin{tabular}{l|l|c|c}
\hline \multirow{4}{*}{ Meios/Locais } & & $\boldsymbol{f}$ & $\mathbf{\%}$ \\
\cline { 2 - 4 } & Em agências de viagem em Natal & 32 & 48,5 \\
\cline { 2 - 4 } & Em agências de viagem no meu Estado & 1 & 1,5 \\
\cline { 2 - 4 } & Ficou sabendo no hotel & 5 & 7,6 \\
\cline { 2 - 4 } & Internet & 7 & 10,6 \\
\cline { 2 - 4 } & Informações de terceiros & 13 & 19,7 \\
\cline { 2 - 4 } & Não sabia, estava incluso no pacote & 6 & 9,1 \\
\cline { 2 - 4 } & Outro & 2 & 3,0 \\
\hline \multicolumn{2}{|c|}{ TOTAL } & $\mathbf{6 6}$ & $\mathbf{1 0 0}$ \\
\hline
\end{tabular}

Fonte: Dados da pesquisa, 2014.

Enquanto a pesquisa de Maracajaú de Silva (2008) apontou que o principal meio de informação foi por meio de terceiros. Assim, vê-se que a divulgação antes feita em Maracajaú se resumia a boca-boca, que segundo os teóricos é uma ferramenta de marketing bastante válida e, com o passar de quatro anos, a divulgação passa de informal para agências de viagens. Percebe-se que a divulgação está sendo constante e eficaz, visto que em Perobas e Maracajaú o fluxo turístico aumenta gradativamente.

Já os motivos da visita ao Parracho são variados, pelo menos oito podem ser vistos na tabela 4, sendo que os principais foram o mergulho $(29,7 \%)$ e a indicação de terceiros $(20,3 \%)$. Os outros $50 \%$ das respostas correspondem à soma dos seguintes motivos: belezas naturais, 
piscinas naturais, por ser preservado, estava incluso no pacote, vida marinha. Os turistas de Macarajaú também apontaram na pesquisa de Silva (2009) que o principal motivo para visitar o destino foi o mergulho, ficando concentrado o fluxo turístico nos recifes de corais (sem outras atividades) para evitar isso seria necessário que as comunidades de Perobas e Maracajaú diversifiquem a oferta turística, como trilhas ecológicas, passeios a cavalo, apresentações culturais e entre outros.

Tabela 4: Motivo da visita a Perobas

\begin{tabular}{l|l|c|c}
\hline \multirow{5}{*}{ Motivos } & & $\boldsymbol{f}$ & \% \\
\cline { 2 - 4 } & Mergulho & 19 & 29,7 \\
\cline { 2 - 4 } & Indicação de terceiros & 13 & 20,3 \\
\cline { 2 - 4 } & Belezas naturais & 7 & 10,9 \\
\cline { 2 - 4 } & Piscinas Naturais & 4 & 6,3 \\
\cline { 2 - 4 } & Ser preservado & 2 & 3,1 \\
\cline { 2 - 4 } & Estava incluso no pacote & 3 & 4,7 \\
\cline { 2 - 4 } & Vida marinha & 2 & 3,1 \\
\cline { 2 - 4 } & Outro & 14 & 21,9 \\
\hline \multirow{7}{*}{ TOTAL } & $\mathbf{6 6}$ & $\mathbf{1 0 0}$ \\
\hline
\end{tabular}

Fonte: Dados da pesquisa, 2014.

Ao serem perguntados quando eles ficaram sabendo que o Parracho faz parte de uma unidade de conservação, 34,3\% dos turistas disserem que souberam antes de chegar a Perobas. Porém, $29,9 \%$ ficaram sabendo ao preencher o questionário e16,4\% ficaram sabendo que o parracho faz parte de uma UC no ônibus indo para o local. E 7,5\% quando chegou a Perobas, antes de fazer o passeio. E alguns na volta do parracho (4,5\%), antes de entrar na água para vê os corais $(3,0 \%)$ e a menos citada na lancha indo para o parracho $(1,5 \%)$.

Tabela 5: Quando o turista fica sabendo que o parracho faz parte de uma APA

\begin{tabular}{l|l|c|c}
\hline \multirow{4}{*}{$\begin{array}{c}\text { Quando o turista } \\
\text { ficou sabendo que } \\
\text { era uma APA }\end{array}$} & Antes de chegar à Perobas & 23 & $\mathbf{f}$ \\
\cline { 2 - 4 } & No ônibus, vindo para Perobas & 11 & 34,3 \\
\cline { 2 - 4 } & Quando chegou à Perobas, ante do passeio & 5 & 16,4 \\
\cline { 2 - 4 } & No catamarã/lancha indo para o parracho & 1 & 7,5 \\
\cline { 2 - 4 } & Antes de entrar na água para vê os corais & 2 & 1,5 \\
\cline { 2 - 4 } & Na volta do parracho & 3 & 4,0 \\
\cline { 2 - 4 } & Ao preencher este questionário & 20 & 29,9 \\
\cline { 2 - 4 } & Outros & 2 & 3,0 \\
\hline \multicolumn{2}{|c|}{ TOTAL } & $\mathbf{6 7}$ & $\mathbf{1 0 0}$ \\
\hline
\end{tabular}

Fonte: Dados da pesquisa, 2014.

Os turistas, em sua maioria (81,5\%), consideram importante saber que o local visitado faz parte de uma UC, ao passo que 18,5\% dos mesmos não consideram esse fato importante (ver Tabela 06). 
Tabela 6: Opinião dos turistas sobre o parracho fazer parte de uma APA

\begin{tabular}{c|l|c|c}
\hline \multirow{2}{*}{$\begin{array}{c}\text { Sobre o parracho fazer } \\
\text { parte de uma APA }\end{array}$} & & $\boldsymbol{f}$ & $\mathbf{\%}$ \\
\cline { 2 - 4 } & Sim & 53 & 81,5 \\
\cline { 2 - 4 } & Não & 12 & 18,5 \\
\hline \multicolumn{2}{l}{ TOTAL }
\end{tabular}

Fonte: Dados da pesquisa, 2014.

Após a pergunta imediatamente anterior, foi peço que eles justificassem a importância dos parracho de Perobas fazerem parte de uma área de proteção ambiental. Dessa forma, foram agrupadas as respostas em sete categorias, como pode ser visto na tabela 7, a seguir.

Tabela 7: Importância atribuída ao parracho fazer parte de uma APA pelos turistas

\begin{tabular}{l|l|c|c}
\hline \multirow{5}{*}{ Importância } & & $\boldsymbol{f}$ & $\mathbf{\%}$ \\
\cline { 2 - 4 } & Ajuda a preservar o local & 37 & 56,1 \\
\cline { 2 - 4 } & Protege as belezas naturais & 4 & 6,1 \\
\cline { 2 - 4 } & Preserva a biodiversidade marinha & 2 & 3,0 \\
\cline { 2 - 4 } & Acesso a futuras gerações & 1 & 1,5 \\
\cline { 2 - 4 } & Ajuda o turismo & 1 & 1,5 \\
\cline { 2 - 4 } & Outros & 5 & 10,6 \\
\cline { 2 - 4 } & Não Responderam & 15 & 22,7 \\
\hline \multicolumn{2}{l}{ TOTAL } & $\mathbf{6 5}$ & 100 \\
\hline
\end{tabular}

Fonte: Dados da pesquisa, 2014.

A primeira categoria Ajuda a Preservar o Local $(56,1 \%)$ agrupou as respostas que indicam que o parracho está sendo preservado, como por exemplo: "proteção ao meio ambiente", “manter sempre a proteção" $e$ "ajuda na preservação".

A categoria Proteger a Beleza Natural $(6,1 \%)$ concentrou resposta ajudar na preservação da beleza natural, como por exemplo: "porque preserva as belezas naturais", "preservar as belezas naturais deve sempre ser um princípio".

Aa terceira, Preserva a Biodiversidade Marinha (3,0\%), reuniu respostas como, "mostra que há preocupação em preservar a biodiversidade marinha na região", "conversar a natureza marinha".

Aa categoria Ajuda o turismo (1,5\%) reuniu respostas como, "deve ser preservado para ajudar o turismo".

A categoria Acesso às Futuras Gerações (1,5\%) reuniu uma única resposta, "para que as futuras gerações possam conhecer e apreciar a natureza". 
E Outros com 10,6\% reuniu respostas que não sentido e não era possível de categorizar, como por exemplo: "muito legal", "não sabia", "ninguém falou”. Por fim, 22, 7\% foram os que não responderam.

Considerável parte dos turistas que visita a $\operatorname{APARC}(59,4 \%)$ não tem acesso às normas do local, ao passo que $40,6 \%$ de turistas tiveram acesso às normas. Como exposto na tabela 8 . Enquanto em Maracajaú 83,8\% dos entrevistados tiveram acesso às normas da APARC (SILVA, 2009).

Tabela 8: Obtenção de informações sobre as normas da APARC

\begin{tabular}{l|l|c|c}
\hline \multirow{3}{*}{ Normas da APARC } & & $\boldsymbol{f}$ & $\mathbf{\%}$ \\
\cline { 2 - 4 } & Sim, eu tive & 26 & 40,6 \\
\cline { 2 - 4 } & Não, eu não tive & 38 & 59,4 \\
\hline \multicolumn{2}{l}{ TOTAL }
\end{tabular}

Fonte: Dados da pesquisa, 2014.

No tocando a Perobas o dado é considerado preocupante, pois mais da metade não tem acesso às normas do local, uma vez que quando fala sobre atividade turística em uma área ambiental protegida que congrega várias normas a fim de preservar o local para garantir maior durabilidade do equilíbrio ecológico e a conservação da beleza cênica é suma importância que os visitantes, a comunidade e as pessoas que trabalham com os passeios terem conhecimento sobre as normas, para evitar que ocorram efeitos nocivos ao local.

Pela falta de conhecimento fica evidente que o local fica sujeito a práticas inadequadas como ancorar nos recifes de corais, alimentação artificial dos peixes, pisoteio e dentre outros.

Em seguida, para os que tiveram acesso as normas, foram feitas perguntas a respeito de quais normas, desse modo, como mostra na tabela 9 a seguir.

Tabela 9: Obtenção de informações sobre as normas da APARC

\begin{tabular}{l|l|c|c}
\hline \multirow{5}{*}{ As normas obtidas } & & $\boldsymbol{f}$ & $\mathbf{\%}$ \\
\cline { 2 - 4 } & Não retirar os corais & 7 & 31,8 \\
\cline { 2 - 4 } & Não pisar nos corais & 3 & 13,6 \\
\cline { 2 - 4 } & Medidas de proteção do passeio (coletes) & 4 & 18,2 \\
\cline { 2 - 4 } & Não jogar lixos & 2 & 9,1 \\
\cline { 2 - 4 } & Preservar o local & 3 & 13,6 \\
\cline { 2 - 4 } & Outros & 3 & 13,6 \\
\hline \multirow{2}{*}{ TOTAL } & $\mathbf{2 2}$ & 100 \\
\hline
\end{tabular}

Fonte: Dados da pesquisa, 2014.

Logo, foi perguntado se os turistas gostariam de visitar um centro de informações sobre o parracho antes de conhecê-lo. Mais da metade $(65,1 \%)$ gostariam de visitar um centro de informação, enquanto $(34,9 \%)$ não preferiam visitar (Ver tabela 10). 
Tabela 10: Turistas gostariam de visitar um centro de informações.

\begin{tabular}{l|l|c|c}
\hline \multirow{3}{*}{ Centro de informações } & & $\boldsymbol{f}$ & $\boldsymbol{\%}$ \\
\cline { 2 - 4 } & Sim & 41 & 65,1 \\
\cline { 2 - 5 } & Não & 22 & 34,9 \\
\hline \multicolumn{2}{|c|}{ TOTAL } & $\mathbf{6 3}$ & $\mathbf{1 0 0}$ \\
\hline
\end{tabular}

Fonte: Dados da pesquisa, 2014.

Considera-se importante que o destino oferte o centro de visitação para aos turistas, pois é o local que tem o objetivo de fornecer informações importantes do parracho para os visitantes. No caso da comunidade de Perobas que oferece passeios em um local que faz parte de uma área de proteção ambiental o centro de visitação mostra-se uma ferramenta imprescindível, visto que seria repassado as informações sobre o ecossistema recifal, a importância da sua preservação e na oportunidade a realização de atividades de sensibilização ambiental.

Quando perguntado aos turistas sobre o seu nível de conhecimento sobre ambientes recifais, $23,1 \%$ dos respondentes têm nenhum conhecimento, 44,6\% têm baixo conhecimento, 26,2 \% têm médio conhecimento e $6,2 \%$ têm alto conhecimento sobre ambientes recifais, como mostra na tabela 11.

Tabela 11: Nível de conhecimento sobre ambientes recifais.

\begin{tabular}{l|l|c|c}
\hline \multirow{4}{*}{$\begin{array}{c}\text { Conhecimento sobre } \\
\text { ambientes recifais }\end{array}$} & Nenhum & $\boldsymbol{f}$ & $\mathbf{\%}$ \\
\cline { 2 - 4 } & Baixo & 15 & 23,1 \\
\cline { 2 - 4 } & Médio & 29 & 44,6 \\
\cline { 2 - 4 } & Alto & 17 & 26,2 \\
\hline \multirow{2}{*}{ TOTAL } & $\mathbf{6 4}$ & $\mathbf{1 0 0}$ \\
\hline
\end{tabular}

Fonte: Dados da pesquisa, 2014.

Isso é outro fato que mostra a importância de um centro de visitantes para Perobas. A maioria dos turistas de Maracajáu que realizaram o passeio (53.8 \%)apresentou também um baixo nível de conhecimento dos recifes de corais (SILVA, 2009), e lá mesmo tento um centro para receber visitantes (prédio) o local não oferece infraestrutura para isso. Ou seja, a APARC não tem condições de receber os visitantes, ficando tudo a cargo das empresas que deixam a desejar.

Quanto ao tempo de permanência do parracho, 65,7\% mostraram está satisfeito com a permanência no parracho, 17,9\% razoável, 9,0\% mais que suficiente e apenas 7,5\% acharam insuficiente, como pode ser visto na tabela 12. 
Tabela 12: Nível de satisfação quanto à permanência no parracho

\begin{tabular}{l|l|c|c}
\hline \multirow{4}{*}{ Permanência } & & $\boldsymbol{f}$ & $\boldsymbol{\%}$ \\
\cline { 2 - 4 } & Suficiente & 44 & 65,7 \\
\cline { 2 - 4 } & Razoável & 12 & 17,9 \\
\cline { 2 - 4 } & Mais que suficiente & 6 & 9,0 \\
\cline { 2 - 4 } & Insuficiente & 5 & 7,5 \\
\hline \multicolumn{2}{|c|}{ TOTAL } & $\mathbf{6 7}$ & 100 \\
\hline
\end{tabular}

Fonte: Dados da pesquisa, 2014.

De modo geral, os turistas se mostraram satisfeitos com a permanência na realização do passeio, isso mostra ser importante, uma vez que turistas satisfeitos contribuem para a divulgação do locam e também podem retornar, o que é importante para a consolidação de um destino turístico.

\section{Considerações Finais}

Pelo exposto neste trabalho, pode-se concluir que quanto à opinião dos turistas sobre o desenvolvimento do turismo nos recifes de corais foi possível constatar que eles mostraram-se satisfeitos com o passeio. Porém, foram repassadas poucas informações sobre o local, sobretudo das normas que existe na APA, comprometendo a conservação e manutenção do local.

Visto não obterem as normas sobre o local, a conduta dos turistas é espontânea e faz que realizem práticas inadequadas, como pisoteio nos corais, alimentação artificial dos peixes. Também ver-se necessária a presença de um monitor ambiental verificando a conduta dos turistas nos passeios, como está previsto no plano de manejo da área, mas foi visto in loco que isso não é realizado, mais uma vez, ficando toda a responsabilidade para as empresas. Um funcionário ligado à APARC que fica na praia próximo ao local de embarque resume-se na contagem dos turistas e embarcações durante o dia e anotações de infrações, mas não tem contato com os visitantes.

Em relação à importância que o turista dá em visitar uma área de proteção ambiental verificase que $(20,9 \%)$ fica sabendo ao preencher o questionário, ou seja, após o término do passeio. Esse dado mostra-se preocupante, para reverter esse quadro seria necessário que o local tenha efetivamente condições de estrutura e pessoas para recebe-los. Uma divulgação eficiente do local também contribuiria para ampliar o conhecimentos do local por parte de seus visitantes, bem como as normas da APARC a fim de que o turista chegue ao local sabendo que existem regras a serem cumpridas, e que isso poderá ajudar na conservação do parracho, permitindo assim que as futuras gerações possam usufruir do local. 


\section{Referências}

AIRES, C. F. Análise da capacidade de inserção produtiva no turismo dos moradores da praia de Perobas-RN. Trabalho conclusão de curso (Graduação em Turismo) Universidade Federal do Rio Grande do Norte. Centro de Ensino Superior do Seridó. Departamento de Ciências Sociais e Humanas. Graduação em Administração. Currais Novos-RN, 2013. 79 f.

AMARAL, R. F. et al. Diagnóstico ambiental da área de uso turístico intensivo (AUTI) no Parracho de Maracajaú. IDEMA-RN, 2005.

BARDIN, L. Análise de conteúdo. Lisboa: Edições 70, 2007.

BRASIL. Lei $n^{\circ}$ 9.985, de 18 de Julho de 2000. Regulamenta o artigo 225, § $1^{\circ}$,incisos I, II, III e VII da Constituição Federal, institui o Sistema Nacional de Unidades de Conservação da Natureza e dá outras providências. Ministério do Meio Ambiente, Brasília. Disponível em: <http://www.mma.gov.br/port/sbf/dap/doc/snuc.pdf>. Acesso em: 02 Ago. 2014.

COSTA, P. C. Unidades de conservação: matéria-prima do ecoturismo. São Paulo: Aleph, 2002.

DENCKER, A. de F. M. Métodos e técnicas de pesquisa em turismo. 6. ed. São Paulo: Futura, 1998.

DIAS, R. Turismo sustentável e meio ambiente. 4. Reimpr. São Paulo: Atlas, 2008.

IDEMA. Área de Proteção ambiental recifes de corais. Disponível em: $<$ http://www.idema.rn.gov.br/Conteudo.asp?TRAN=ITEM\&TARG=944\&ACT=\&PAGE=0\&PARM= $\& \mathrm{LBL}=$ Unidades+de+Conserva\%E7\%E3o $>$. Acesso em: 24 Out. 2013.

KUNZMANN, A. Corals, fishermen and tourists. NAGA, WorldFish Center Quarterly Vol. 27 No. 1 \& 2 Jan-Jun 2004.

OMT. Introdução ao turismo. São Paulo: Ed. Rocca, 2001.

PRATES; A. P. L; GONÇALVES, M. A; ROSA, M. R. Panorama da conservação dos ecossistemas costeiros e marinhos no Brasil. 2. ed. rev. ampliada. Brasília: MMA, 2012.

RIO GRANDE DO NORTE. Decreto n. ${ }^{\circ} 15.746$, de 06 de junho de 2001. Dispõe sobre criação de Área de Proteção Ambiental - APA dos Recifes de Corais. Disponível em: <http:// www.idema.rn.gov.br/contentproducao/aplicacao/idema/unidades_de_conservacao/ gerados/recifes_corais.asp> Acesso em: 12 Ago. 2014.

SANTOS, T. C. C.; CÂMARA, J. B. D. (Org.) GEO BRASIL 2002, perspectivas do meio ambiente no Brasil. Brasília: IBAMA, 2002. 447p.

SILVA, C. B. Análise da atividade turística desenvolvida na área de proteção ambiental dos Recifes de Corais - RN / 2009. 119 f. Dissertação (Mestrado) - Universidade Federal do Rio Grande do Norte. Pro - Reitoria de Pós-Graduação. Programa Regional de Pós-Graduação em Desenvolvimento e Meio Ambiente/PRODEMA. Natal-RN, 2009.

\section{Recebido em: $28 / 04 / 2016$ ( $1^{\text {a }}$ versão) $05 / 08 / 2016$ ( $2^{\text {a }}$ versão) Aprovado em: 05/08/2016}

